\title{
IMPACT OF URINAY INCONINENCE ON FEMALE SEXUAL LIFE
}

Mostafa Ahmed Hamdy Department of Obstetrics and Gynecology, Faculty of Medicine, Suez Canal University, Egypt

Nahed Amin Eldahshan Department of Family Medicine, Faculty of Medicine, Suez Canal University, Egypt
Mostafa Ahmed Hamdy Department of Obstetrics and Gynecology, Faculty of Medicine, Suez Canal University, Egypt
Background: Urinary incontinence (UI), involuntary escape of urine, is a common problem affecting (10-55\%) of women but also a hidden issue. It could have a distressing influence on the social, familiar and sexual functions of the patients.

Aim: The aim of this study was to evaluate the impact of UI on the female sexual function (FSF). Material and Methods: This casecontrol questionnaire-based study was conducted at Suez Canal University Hospitals, Ismailia at outpatient clinic from March 2016 to August 2017. Sixty nine patients with UI and 63 women free of UI were evaluated. Data on FSF were obtained by female sexual function index (FSFI) questionnaire. A score of 26.55 was the cut point between normal FSF and deficient sexual function (DSF).

Results: The means of the six domains of the (FSFI) were significantly different between both groups $(\mathrm{p}<0.001)$. Stress UI had the poorest effect on all the FSFI domains except the satisfaction and pain domains were related to the other types.

Conclusion: UI had a major poor effect on the female sexual function.

Keywords: Female sexual function, sexual satisfaction, female sexual function questionnaire, urinary incontinence.

\section{Introduction}

Urinary incontinence (UI) defined as any invo $\neg$ luntary escape of urine. It is usually associated with social, psychological, sexual and hygie $\neg$ nic distress, according to the classification of International Continence Society and Internatio $\neg$ nal Urogynecological Association (1). Its prevalence in women is about 10 to $55 \%$ and it is considered a high percentage, put in mind it is a hidden problem, as large portion of patients don't seek medical advice (2).

UI is an essential public health problem due to high prevalence and poor consequence on quality of life (3) and due to economic costs of management (4). So that, clinical assessment of pelvic floor dysfunction and its consequences, UI and pelvic organ prolapse (POP), gained high recommendations and practical guide $\neg$ lines (2-5).

UI has a bad effect on the quality of female sexuality and may lead to complete drop of sexual activity in a high proportion of cases (6-11). It was accepted that UI has dramatic impact on the sexual function in middle-aged sexually active women; proposed mechanisms include dyspareunia and coital incontinence in addition to the bad psychological and emotional related issues (12-19).

At the time of writing such article it is not sure whether the sexual problems associated with incontinence are directly related to incontinence itself or are caused by co-morbid factors, pelvic floor impairment (20). Defining what role UI plays in female sexuality 
is challenging and not clearly apparent, due to the complex etiology of sexual dysfunction, multifactorial, to the taboo nature of both disorders and the significant difference in the methods used for investigations (4).

The target of that study was to evaluate the impact of UI and its common types on the female sexual life.

\section{Materials and Methods}

Following the acceptance by the Ethics Committee of the Faculty of Medicine, Suez Canal University this case-control questionnaire-based study was carried out at the Obstetrics and Gynecology Department of the Suez Canal University Hospitals, Ismailia from March 2016 to August 2017. All participants gave oral and written informed consent before to be recruited into the study.

In order to obtain a power of $80 \%$, a sample size of 65 was calculated for each group. This was based on the prevalence rate of UI is about $15 \%$, a standard normal variance at $95 \%$ confidence interval (CI) of 1.96 , and absolute standard error of 0.05 . However in order to take care of attrition a total of 75 women were recruited for each group (21).

Seventy five patients were included from those women who presented or were referred to the hospital for management of the UI (stress, mixed or urge) they were the study (UI) group. Another 75 women without evidence of any type of UI were also studied and were considered the control group.

The inclusion criteria were age is between (20-50) years old, sexually active and reliable patient. The women in the control group were with no evidence of UI. Exclusion criteria included evidence of psychiatric disorders, neurological findings, sexually inactive, unreliable patient or had abnormal male husband. Women with vaginal support defects greater than second stage according to the Pelvic Organ Prolapse Quantification (POPQ) system were excluded to avoid or at least minimize the effect of (POP) on the FSF.

All recruited women were submitted to a complete medical history, including name, age, job, educational level, smoking status, parity, and mode of the delivery. Age was categorized into 3 groups: 20-30 years, $31-40$ years and $41-50$ years. Job was classified into house wife, employee and advanced employee. Educational level was categorized as uneducated, educated and highly educated. Smoking status was categorized as non smoker or smoker. By parity, women were classified as nullipara, multipara, grand multipara. Mode of delivery was either by vaginal delivery (VD) or by cesarean section (CS). BMI was grouped into 4 categories: under weight $\left(<19 \mathrm{~kg} / \mathrm{m}^{2}\right)$, average weight $\left(19-24.9 \mathrm{~kg} / \mathrm{m}^{2}\right)$, over weight $\left(25.0-29.9 \mathrm{~kg} / \mathrm{m}^{2}\right)$, obese $\left(30.0-39.9 \mathrm{~kg} / \mathrm{m}^{2}\right)$ and morbidly obese $\left(\geq 40 \mathrm{~kg} / \mathrm{m}^{2}\right)$.

Physical examination of the cases includes general and local evaluation. On local gynecological assessment the maximal extent of prolapse was measured during a Valsalva maneuver or coughing. The most marked protrusion was assessed using the (POPQ); stage 0, no prolapse is demonstrated; stage 1 , the most distal portion of the prolapse is more than $1 \mathrm{~cm}$ above the level of the hymen; stage 2 , the most distal portion of the prolapse is $1 \mathrm{~cm}$ or less proximal or distal to the hymen plane; stage 3 , the most distal portion of the prolapse protrudes more than $1 \mathrm{~cm}$ below the hymen but protrudes no farther than $2 \mathrm{~cm}$ less than the total vaginal length (for example., not all of the vagina has prolapsed); stage 4, vaginal eversion is essentially complete (22).

A stress cough test was done to establish the presence of UI. The severity of UI was classified according to the Stamey incontinence score; grade 0, continent; grade 1, loss of urine with sudden increases in abdominal pressure (coughing, sneezing, laughing); grade 2, leaks with lesser degrees of physical stress, such as walking, standing erect from a sitting position, or sitting up in bed; grade 3, total incontinenceurine is lost without any relation to physical activity or position) (23).

Complete urinanalysis and culture were done routinely for the patients of the UI group and management was completes for such patients prior to entering the study. Also any resistant cases were excluded from the study and were referred to a specialist.

Urodynamic evaluation, for the study group(UI) only, was performed with 2 urethral catheters cystometry. The involuntary detrusor contractions during the filling phase may be spontaneous or provoked giving the diagnosis of urge urinary incontinence (UUI). Stress urinary incontinence (SUI) is usually associated with normal filling capacity and urine leak during the increase in intra abdominal pressure in absence of detrosus muscle contraction. Coincidence of both raises the diagnosis of mixed urinary incontinence (MUI) (24).

Data on FSF, and satisfaction were obtained from FSFI questionnaire, from 150 (75 patients and 75 
controls) women. The FSFI questionnaire is based on 19 questions dealing with six domains of FSFI (desire, arousal, lubrication, orgasm, satisfaction, and pain). For this study, the Arabic translation was used. The translation was based on the original FSFI questionnaire and was validated (25). Responses to each question related to the previous 4 weeks were recorded and scored either from 0 (no sexual activity) or 1 (indicating dysfunction) to 5 (indicating normal function). Each domain scores are collected by adding the scores of its questions and multiplying the sum by the domain factor provided in the FSFI for each domain. The full scale score was obtained by adding the six domain scores (minimum score possible was two and the maximum was 36). Regarding the cutoff point, a total FSFI score of less than 26.55 was considered as sexual dysfunction (26).

The primary outcome measure of that work was to assess the influence of UI and its common types on the female sexual life. Also the contribution of the degree POP on each type of the UI was evaluated.

\section{Statistical Analysis}

Data were statistically described in terms of mean and standard deviation, frequencies (number of cases) and percentages when appropriate. Comparison between both groups was done using Chi-Square test in the cross tabulation of the socio-demographic data between both groups and independent sample test to compare six domains of the FSFI between both groups and one-way Anova test to compare six domains of the FSFI among the three types of UI. $P$ values less than 0.05 were considered statistically significant. Also spearman Chi-Square test was used for correlation between the stages of POPQ and types of UI. All statistical calculations were done using computer program SPSS (Statistical Package for the Social Science; SPSS Inc., Chicago, IL, USA) release 22 for Microsoft Windows.

\section{Flowchart}

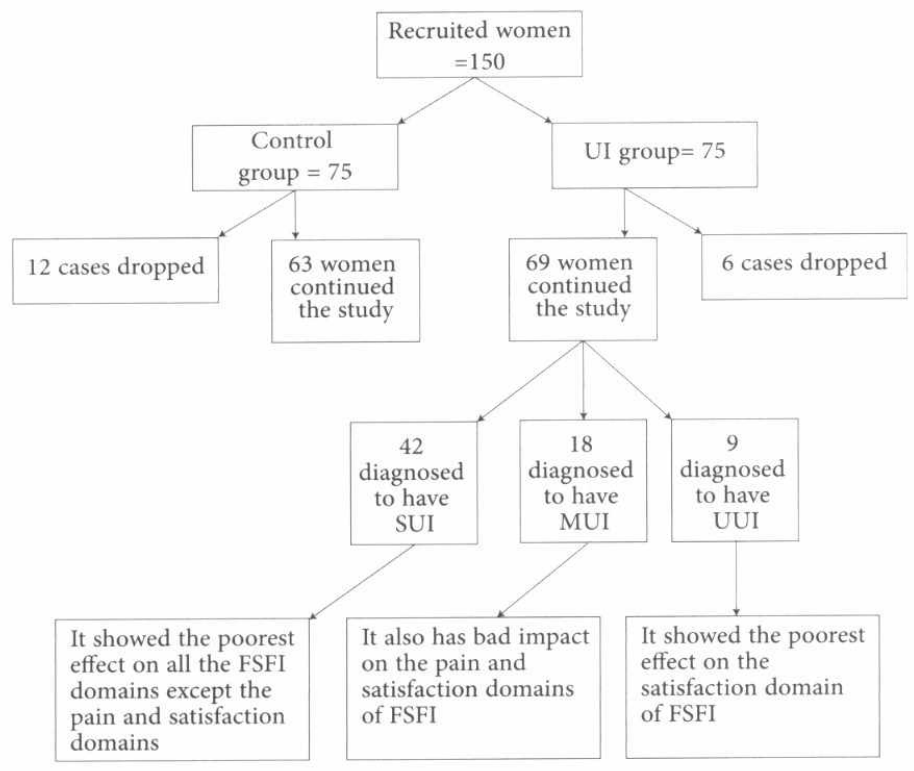

\section{$\underline{\text { Results }}$}

Seventy five patients were randomly selected from those women with evidence of UI; they were the study (UI) group. Another 75 women free of UI were also randomly selected and were considered the control group. Eighteen women were dropped out, 6 from UI group and 12 from the control group (didn't come, refuse urodynamic study or discovered to have a chronic illness). So the net population in the study was 132 women; 63 women for the control group and 69 women for the studied (UI) group. The UI group was further subdivided according to the cystometric evaluation into 42 patients with SUI, 18 patients with MUI and 9 patients with UUI.

The mean age for all the whole studied population was $(38.8 \pm 7.2)$ years ranged from 20 to 50 years old. Table (I) showed the distribution of the demographic data between the both groups. Of note that the mean age for UI group was (39.7 \pm 6.1$)$ and for the control group was (37.9 \pm 8.1$)$ which showed insignificant difference statistically ( $\mathrm{p}$ value 0.135 ). Most of our patients were non smoker $(85.7 \% \& 82.6 \%)$, MP (71.4\% \& $73.9 \%)$ \& delivered vaginally $(76.2 \% \&$ $69.6 \%$ ) for the control and the UI group respectively. 
Table (I): Demographic criteria among the both groups.

\begin{tabular}{|c|c|c|c|c|c|c|}
\hline & \multicolumn{2}{|c|}{ Control group } & \multicolumn{2}{|c|}{ UI } & \multirow{2}{*}{ Pvalue* } \\
\hline & & NO. & $\%$ & NO. & $\%$ & \\
\hline \multirow{4}{*}{$\begin{array}{l}\text { Age group } \\
\text { (years) }\end{array}$} & $20-30$ & 15 & 23.8 & 9 & 13 & \multirow{3}{*}{0.068} \\
\hline & $31-40$ & 21 & 33.3 & 36 & 52.2 & \\
\hline & $41-50$ & 27 & 42.9 & 24 & 34.8 & \\
\hline & Mean \pm SD & \multicolumn{2}{|c|}{$37.9 \pm 8.1$} & \multicolumn{2}{|c|}{$39.7 \pm 6.1$} & $0.135 \bullet$ \\
\hline \multirow{3}{*}{ Job } & House wife & 21 & 33.3 & 12 & 17.4 & \multirow{3}{*}{0.097} \\
\hline & Employee & 24 & 38.1 & 30 & 43.5 & \\
\hline & $\begin{array}{l}\text { Advanced } \\
\text { Employee }\end{array}$ & 18 & 28.6 & 27 & 39.1 & \\
\hline \multirow{3}{*}{ Education } & Uneducated & 21 & 33.3 & 12 & 17.4 & \multirow{3}{*}{0.097} \\
\hline & Educated & 24 & 38.1 & 30 & 43.5 & \\
\hline & $\begin{array}{c}\text { Highly } \\
\text { educated }\end{array}$ & 18 & 28.6 & 27 & 39.1 & \\
\hline \multirow{2}{*}{ Smoking } & Non-smoked & 54 & 85.7 & 57 & 82.6 & \multirow{2}{*}{0.403} \\
\hline & Smoker & 9 & 14.3 & 12 & 17.4 & \\
\hline \multirow{3}{*}{ Parity } & PG & 9 & 14.3 & 12 & 17.4 & \multirow{3}{*}{0.567} \\
\hline & MG & 45 & 71.4 & 51 & 73.9 & \\
\hline & GMP & 9 & 14.3 & 6 & 8.7 & \\
\hline \multirow{2}{*}{ Mode } & VD & 48 & 76.2 & 48 & 69.6 & \multirow{2}{*}{0.256} \\
\hline & CS & 15 & 23.8 & 21 & 30.4 & \\
\hline \multirow{3}{*}{ BMI } & Average & 6 & 9.5 & 9 & 13 & \multirow{3}{*}{0.566} \\
\hline & Overweight & 24 & 38.1 & 30 & 43.5 & \\
\hline & Obese & 33 & 52.4 & 30 & 43.5 & \\
\hline
\end{tabular}

$*=$ Chi square, $\bullet=$ Independent sample test, $\mathrm{PG}=$ primigravida, $\mathrm{MG}=$ multigravida, $\mathrm{GMP}=$ grand multipara, $\mathrm{VD}=$ vaginal delivery, $\mathrm{CS}=$ cesarean section, $\mathrm{BMI}=$ body mass index, $\mathrm{UI}=$ urinary incontinence.

Also the BMI showed that most of them were obese $(52.4 \& 43.5 \%)$ respectively. Of note all the sociodemographic data showed no significant difference between both groups ( $\mathrm{p}$ value $>0.05$ ).

Tale (II) represented the distribution of the POPQ stages among the types of UI; SUI, UUI, and MUI. Of note most of the patients with SUI and MUI were in the second stage of the POPQ $(85.7 \%$ and $44.4 \%)$ respectively, while most of the patients with UUI were in the first stage of the POPQ $(55.6 \%)$ which represented a significant difference $(\mathrm{p}$ value $<0.001)$. Also there was a reasonable level of correlation (Pearson's $\mathrm{R}=0.4$ ).

Table (II): Distribution of POPQ degrees among the three types of UI.

\begin{tabular}{|c|c|c|c|c|c|c|c|c|c|c|}
\hline \multirow{3}{*}{$\underset{\text { TI }}{\text { TYPE of }}$} & \multicolumn{6}{|c|}{ POPQ } & \multirow{2}{*}{\multicolumn{2}{|c|}{ TOTAL }} & \multirow{3}{*}{$\begin{array}{c}\text { Spearmn } \\
\mathbf{R}^{\circ}\end{array}$} & \multirow{3}{*}{ Pvalue* } \\
\hline & \multicolumn{2}{|c|}{ Stage (0) } & \multicolumn{2}{|c|}{ Stage (I) } & \multicolumn{2}{|c|}{ Stage (II) } & & & & \\
\hline & NO. & $\%$ & NO. & $\%$ & NO. & $\%$ & NO. & $\%$ & & \\
\hline SUI & 3 & 7.1 & 3 & 7.1 & 36 & 85.7 & 42 & 100 & \multirow{3}{*}{0.514} & \multirow{3}{*}{$<0.001$} \\
\hline UUI & 3 & 33.3 & 5 & 55.6 & 1 & 11.1 & 9 & 100 & & \\
\hline MUI & 4 & 22.2 & 6 & 33.3 & 8 & 44.5 & 18 & 100 & & \\
\hline
\end{tabular}


$*=$ Chi square ${ }^{\mathrm{o}}=$ spearman Chi-square, correlation, $\mathrm{UI}=$ urinary incontinence, $\mathrm{SUI}=$ stress urinary incontinence. $\mathrm{UUI}=$ urge urinary incontinence. $\mathrm{MUI}=$ mixed urinary incontinence, $\mathrm{POPQ}=$ Pelvic Organ Prolapse Quantification.

Table (III): FSFI among the both groups.

\begin{tabular}{|c|c|c|c|c|c|c|c|}
\hline \multirow{2}{*}{ FSFI DOMAIN } & \multirow{2}{*}{ Group } & \multirow{2}{*}{$\underset{\text { SD }}{\operatorname{Mean} \pm}$} & \multicolumn{2}{|c|}{$\begin{array}{l}95 \% \text { Confidence } \\
\text { Interval of the } \\
\text { Difference }\end{array}$} & \multirow[t]{2}{*}{ t } & \multirow{2}{*}{ df } & \multirow{2}{*}{ P value• } \\
\hline & & & $\begin{array}{l}\text { Lower } \\
\text { Bound }\end{array}$ & $\begin{array}{l}\text { Upper } \\
\text { Bound }\end{array}$ & & & \\
\hline \multirow{2}{*}{ DESIRE } & CONTROL & $4.7 \pm 0.56$ & 0.51813 & 1.19367 & \multirow{2}{*}{5.013} & \multirow{2}{*}{130} & \multirow{2}{*}{$<0.001$} \\
\hline & UI & $3.9 \pm 1.2$ & 0.52720 & 1.18461 & & & \\
\hline \multirow{2}{*}{ AROUSAL } & CONTROL & $5 \pm 0.43$ & 0.73677 & 1.36385 & \multirow{2}{*}{6.627} & \multirow{2}{*}{130} & \multirow{2}{*}{$<0.001$} \\
\hline & UI & $3.98 \pm 1.9$ & 0.74614 & 1.35449 & & & \\
\hline \multirow{2}{*}{ LUBRICATION } & CONTROL & $4.8 \pm 0.4$ & 0.90846 & 1.49899 & \multirow{2}{*}{8.065} & \multirow{2}{*}{130} & \multirow{2}{*}{$<0.001$} \\
\hline & UI & $3.6 \pm 1.1$ & 0.91773 & 1.48972 & & & \\
\hline \multirow{2}{*}{ ORGASM } & CONTROL & $5 \pm 0.44$ & 0.64389 & 0.10021 & \multirow{2}{*}{7.562} & \multirow{2}{*}{130} & \multirow{2}{*}{$<0.001$} \\
\hline & UI & $4.2 \pm 0.8$ & 0.64906 & 1.09504 & & & \\
\hline \multirow{2}{*}{ SATSFACTION } & CONTROL & $5 . \pm 0.3$ & 0.57304 & 0.96567 & \multirow{2}{*}{7.753} & \multirow{2}{*}{130} & \multirow{2}{*}{$<0.001$} \\
\hline & UI & $4.3 \pm 0.7$ & 0.57901 & 0.95971 & & & \\
\hline \multirow{2}{*}{ PAIN } & CONTROL & $2.7 \pm 0.4$ & -1.91547 & -1.47169 & \multirow{2}{*}{-15.100} & \multirow{2}{*}{130} & \multirow{2}{*}{$<0.001$} \\
\hline & UI & $4.4 \pm 0.8$ & -1.91067 & -1.47650 & & & \\
\hline \multirow{2}{*}{ TOTAL SCORE } & CONTROL & $27.4 \pm 1.2$ & 2.01923 & 4.09630 & \multirow{2}{*}{5.825} & \multirow{2}{*}{130} & \multirow{2}{*}{$<0.001$} \\
\hline & UI & $24.4 \pm 4$ & 2.05255 & 4.06298 & & & \\
\hline
\end{tabular}

•=Independent sample test, FSFI= Female sexual function index, UI= urinary incontinence.

Table (III) showed highly significant difference among the means of the six domains of the FSFI between the both groups ( $p$ value $<0.001$ ). It meant that most patients in the UI group had (DSF).

In table (VI) we could compare the impact of each type of UI on each domain of the FSFI. SUI had the least scores significantly in all the FSFI domains except the satisfaction and pain domains ( $p$ value $<0.001)$. UUI was the second distressing type of UI after the SUI on the mentioned domains and was the worst on the satisfaction domain ( $\mathrm{p}$ value $<0.001$ ).

Table (VI): FSFI among the types of UI.

\begin{tabular}{|c|c|c|c|c|c|c|}
\hline \multirow{2}{*}{ FSFI DOMAIN } & \multirow{2}{*}{ TYPE } & \multirow{2}{*}{$\underset{\text { SD }}{\operatorname{Mean} \pm}$} & \multicolumn{2}{|c|}{$\begin{array}{l}\text { 95\% Confidence Interval } \\
\text { for Mean }\end{array}$} & \multirow{2}{*}{ f } & \multirow{2}{*}{ P value• } \\
\hline & & & $\begin{array}{l}\text { Lower } \\
\text { Bound }\end{array}$ & $\begin{array}{l}\text { Upper } \\
\text { Bound }\end{array}$ & & \\
\hline \multirow{3}{*}{ DESIRE } & SUI & $3.7 \pm 1.2$ & 3.3240 & 4.0760 & \multirow{3}{*}{9.838} & \multirow{3}{*}{$<0.001$} \\
\hline & UUI & $4.1 \pm 1.6$ & 2.9035 & 5.3632 & & \\
\hline & MUI & $4.2 \pm 1.1$ & 3.6395 & 4.7605 & & \\
\hline \multirow{3}{*}{ AROUSAL } & SUI & $3.8 \pm 1.1$ & 3.4668 & 4.1618 & \multirow{3}{*}{13.677} & \multirow{3}{*}{$<0.001$} \\
\hline & UUI & $3.9 \pm 1.3$ & 2.8325 & 4.9008 & & \\
\hline & MUI & $4.4 \pm 1.2$ & 3.8073 & 5.0260 & & \\
\hline
\end{tabular}




\begin{tabular}{|c|c|c|c|c|c|c|}
\hline \multirow{3}{*}{ LUBRICATION } & SUI & $3.5 \pm 1.1$ & 3.1227 & 3.7773 & \multirow{3}{*}{17.430} & \multirow{3}{*}{$<0.001$} \\
\hline & UUI & $3.7 \pm 1.1$ & 2.8219 & 4.5781 & & \\
\hline & MUI & $4.1 \pm 1.3$ & 3.4249 & 4.6751 & & \\
\hline \multirow{3}{*}{ ORGASM } & SUI & $4 \pm 0.8$ & 3.7879 & 4.2692 & \multirow{3}{*}{9.156} & \multirow{3}{*}{$<0.001$} \\
\hline & UUI & $4.1 \pm 0.9$ & 3.4632 & 4.8034 & & \\
\hline & MUI & $4.5 \pm 0.9$ & 4.0503 & 4.8831 & & \\
\hline \multirow{3}{*}{ SATSFACTION } & SUI & $4.2 \pm 0.6$ & 3.9896 & 4.3913 & \multirow{3}{*}{7.130} & \multirow{3}{*}{$<0.001$} \\
\hline & UUI & $4.1 \pm 1.1$ & 3.2774 & 4.9893 & & \\
\hline & MUI & $4.6 \pm 0.7$ & 4.1936 & 4.9175 & & \\
\hline \multirow{3}{*}{ PAIN } & SUI & $4.5 \pm 0.9$ & 4.2706 & 4.8151 & \multirow{3}{*}{32.048} & \multirow{3}{*}{$<0.001$} \\
\hline & UUI & $4.2 \pm 0.6$ & 3.7844 & 4.6601 & & \\
\hline & MUI & $4.2 \pm 0.6$ & 3.9231 & 4.5214 & & \\
\hline \multirow{3}{*}{ SCORE } & SUI & $23.7 \pm 3.3$ & 22.6828 & 24.7696 & \multirow{3}{*}{122.784} & \multirow{3}{*}{$<0.001$} \\
\hline & UUI & $24 . \pm 5.6$ & 19.9163 & 28.4615 & & \\
\hline & MUI & $25.9 \pm 4.4$ & 23.7419 & 28.0803 & & \\
\hline
\end{tabular}

-=One way Anova test, FSFI= Female sexual function index, SUI= stress urinary incontinence. UUI= urge urinary incontinence. $\mathrm{MUI}=$ mixed urinary incontinence.

\section{$\underline{\text { Discussion }}$}

In this work we analyzed the impact of the UI and its common types on the female sexuality using the FSFI, a solid and validated questionnaire. The net result of our study was that UI had a major poor impact on all the domains of the FSFI and it means that almost all the females with UI (SUI, UUI or MUI) had a bad sexual life and by the way a very poor impact on their quality of life.

We could explain such poor impact of the UI on the female sexual life by many factors; first was the bad effect of the urine, on the vulva and vagina, and the associated vulvovaginitis could be a major contributing reason of the superficial dyspareunia. Second was the resulted coital incontinence which may be with the penetration of the vagina, SUI, with deeply sexual act and orgasm, UUI, or combined, MUI. Third was the associated vaginal or uterine prolapse can be a solid cause of dyspareunia and deficient sexual act. Such factor is clearly apparent in advanced stages of prolapse which was excluded in our study. Fourth was the very bad psychological and emotional sequlae of the UI on the patient, shame and fear of incontinence, affect her desire for the sexual practice.

This thought was approved by Oh SJ et al, 2008, who augmented that embarrassment, fear of urine leak, urge sensation during sexual act and the response of the partner were the main factors causing female sexual dysfunction (10). Also Karbage et al, 2016, found that urinary incontinence could affect poorly female sexual life, namely: loss of urine during coital relation, night losses associated to urgency and fear of bedwetting (11).

Jha $\mathrm{S}$ et al, 2012, found that fear of very bad smell and urinary incontinence during intercourse is associated with alteration of image, confidence and self-respect causing reduced desire of sexual act among such women. In elderly population, in the presence of a sexual partner, the occurrence of urinary incontinence has a negative impact on sexuality (12).

This study showed that the SUI had the poorest effect on the female sexuality, namely; desire, arousal, lubrication and orgasm domains. We could explain that by; first the associated superficial dyspareunia during the penetration of the vagina could cause increases intraabdominal pressure with the resulted SUI so the start of the sexual act could be interrupted greatly and by logic the following stages of the female sexual cycle would be affected disappointingly. Second, the activity that increases intra-abdominal pressure during sexual intercourse would aggravate the leak o urine. Third, the fear of bad smell and leak of urine during coitus is associated with under estimation of image and self-esteem. All seem as logic causes 
of diminished rate of sexual activity among those women (13-16).

Our results were supported by most of the previous studies that suggest urinary leakage occurs during sexual activity in $11 \%$ to $60 \%$ of women with stress urinary incontinence. This large range likely reflects methodological and population differences among the studies and the small sample sizes (17-19).

Another study by Lam et al, a self-administered questionnaire was mailed to a random sample of women living in Aarhus, Denmark. Overall, 12\% of 441 women with stress urinary incontinence reported leakage during sexual intercourse (20).

We accepted a previous result by Barber et al, 2002, showed that feeling more pain and urine leakage during sexual intercourse had been reported to be more common in women with stress urinary incontinence than in those with overactive bladder (27).

In a case-control study, by Hilton, twenty three percent of the women with stress incontinence experienced incontinence during intercourse. Of these women, 18\% reported incontinence during penetration and 5\% during orgasm (22). These results were supported by those of Clark and Romm, who concluded that leakage was more likely to occur during penetration than during arousal, orgasm, or resolution (23). These two studies were side by side to our results, as if the female sexual cycle was interrupted during the penetration of the vagina definitely the rest of the cycle would be interrupted, arrested or cancelled, so the other domains will be defectively affected.

We demonstrated that UUI was the second distressing type of UI on the mentioned FSFI domains and was the worst type of UI on the satisfaction domain. It could be explained by the fact that the etiology of the UUI in some cases is related to pathology within the urinary bladder, $\mathrm{UB}$, (infection, stone), and as the UB is a pelvic organ, pelvic congestion could be a result. So with the deep sexual act, a severe pain and congestion could trigger of the detrosur muscle causing the urine leak. Surely it would affect her orgasm and satisfaction and the way the continuation of the sexual process totally.

We agreed previous studies that concluded sexual activity was found to be significantly reduced in women with overactive bladder syndrome compared to that in asymptomatic subjects (24).
In the opposite of our results Asoglu (2014) found that urgency symptoms, particularly if associated with MUI, were related to anxiety, mood instability (depression symptoms) while poor quality of life related to SUI in the circumstances of sexual life (1). Su, et al (2015) evaluated female sexual response in case of urinary incontinence, using international validated questionnaires (FSFI) and concluded differences among different domains of FSFI according to different types of urinary incontinence. UUI related to reduction to lubrication and increase of pain associated to sexual activity. MUI was related to reduction of sexual satisfaction while SUI did not present any impact on sexual relation (25).

Also Gordon and his colleagues have found that total sexual function scores in subjects with (UUI) were lower than in those with stress urinary incontinence (26). Those results accepted those found by $\mathrm{Oh}$ et al who investigated 245 women with stress urinary incontinence and overactive bladder on female sexual dysfunction they found that the rate of female sexual dysfunction in women with UUI was higher than in those with SUI (14).

We could explain the conflict of such results and ours by the small sample size of our study in addition to the prevalence of each type of UI. In our work we could see that $60.9 \%$ our UI group had SUI, 26.1\% had MUI and 13\% had UUI and such figures approximate significantly the world wide prevalence. So that the largest portion of our UI patients were in the SUI subgroup and by the way the apparent more effect of SUI on FSF.

This work showed a significant difference statistically regarding the distribution of the studied types of UI (SUI, UUI and MUI) on the POPQ stages and such results are in agreement regarding the etiology and risk factors for the development of a particular type of UI. But we could augment that it would added no statistically bias our results. This can be explained by many factors; first, we excluded any patient with more than stage (II) POPQ. Second, $88.9 \%$ and $55.5 \%$ of UUI and MUI patients' respectively had no POP or were in the stage (I) POPQ and $11.1 \%$ and $44.5 \%$ were in the stage (II). It could reflect the little change in the anatomical support of the neck of the UB on such patients.

Also Handa et al screened the effect of PFD on the FSF by evaluating 495 women with evidence of PFD and found that UI was significantly associated 
with low libido, vaginal dryness, and dyspareunia, but POP has no sexual complaint (28). Barber et al reported $81 \%$ of sexually active patients reacted to sexual intercourse as 'somewhat' or 'very' satisfactory, and that POP had no impact (27).

\section{Limitations of the study}

Our study has a few limitations. One was the small sample size of our study. Second was the small percentage of each type of UI, which was related to the small sample size. Of course there was some sort of difficulty to obtain such sensitive data due to cultural and religions obstacle.

\section{Conclusions}

Urinary incontinence affects unhelpfully female sexuality. Fear of familiarity associated to sex action is apparent in view of the decreased frequency of sexual life and global satisfaction indices among incontinent women. Also our results concluded that SUI was has the poorest impact on the female sexual function.

We recommended for larger studies based on randomized clinical trials to clearly establish the effect of UI and its subtypes on the female sexuality and evaluate the available lines of management.

\section{Disclosure}

The authors reported no conflicts of interest.

\section{Refferences:}

1. Asoglu MR, Selcuk S, Cam C et al. Effects of urinary incontinence subtypes on women's quality of life (including sexual life) and psychosocial state. Eur J Obstet Gynecol Reprod Biol. 2014; the 176:187-90.

2. Hu TW, Wagner TH, Bentkover JD, et al. Estimated economic costs of overactive bladder in the United States. Urology. 2003; 61:1123-8.

3. Burkhard FC, Lucas MG, Berghmans LC, et al. Guidelines on Urinary Incontinence. EAU Guidel Ed. Present 30th EAU Congr Madrid. 2016;available at $<$ http://uroweb.org/ guidelines $>$.

4. R. Botlero DM, Urquhart, S R Davis et al. "Prevalence and incidence of urinary incontinence in women: review of the literature and investigation of methodological issues," International Journal of Urology. 2008; vol.15,no.3,pp.
5. O. Dalpiaz, A. Kerschbaumer, M. Mitterberger et al. "Female sexual dysfunction: a new urogynaecological research field," BJU International. 2008; vol.101,no.6,pp. 717-721.

6. StameyT. A. Endoscopic suspension of the vesical neck for Urinary incontinence. Surg gynecol.Obstet. 1973;136:547-554.

7. Nancy L, and Shlomo R. Urodynamics. In Hervert B. Joseph S. (eds) Gynecol and Obestst. Urology. W.B. Saunders company Philadelphia. 1993;265-283.

8. Anis TH, AboulGheit S, Awad HH et al .Effects of female genital cutting on the sexual function of Egyptian women. A cross-sectional study. J Sex Med. 2012; 9(10): 2682-2692.

9. Rosen R, Brown C, Heiman J, et al.The Female Sexual Function Index (FSFI): A Multidimensional Self- Report Instrument for the Assessment of Female Sexual Function. J Sex Marital Ther. 2000; 26 (2): 191-208.

10. Oh SJ, Ku JH, Choo MS et al. Health-related quality of life and sexual function in women with stress urinary incontinence and overactive bladder. Int J Urol. 2008; 15:62-67.

11. Karbage SA, Santos ZM, Frota MA et al. Quality of life of Brazilian women with urinary incontinence and the impact on their sexual function. Eur J Obstet Gynecol Reprod Biol. 2016;201:5 6-60.

12. Jha S, Ammenbal M, Metwally M. Impact of incontinence surgery on sexual function: a systematic review and metanalysis. J Sex Med. 2012; 9:34-43.

13. Salama S, Boitrelle F, Gauquelin A et al. Nature and origin of "squirting" in female sexuality. J Sex Med. 2015; 12:661-6.

14. El-Azab AS, Yousef HA, Seifeldein GS. Coital incontinence: relation to detrusor overactivity and stress incontinence. Neurourol Urodyn. 2011; 30:520-4.

15. Pastor Z. Female ejaculation orgasm vs. coital incontinence: a systematic review. J Sex Med. 2013; 10:1682-91.

16. Madhu C, Hashim H, Enki D et al. Coital incontinence: what can we learn from urodynamic assessment? Urology. 2015; 85:1034-8. 
17. Visser E, de Bock GH, Berger MY et al. Impact of urinary incontinence on sexual functioning in community dwelling older women. J Sex Med. 2014; 11:1757-65.

18. Fatton B, de Tayrac R, Costa P. Stress urinary incontinence and LUTS in women--effects on sexual function. Nat RevUrol. 2014;11:565-78.

19. Bo K, Talseth T, Vinsnes A. Randomized controlled trial on the effect of pelvic floor muscle training on quality of life and sexual problems in genuine stress incontinent women. Acta Obstet Gynecol Scand 2000;79:598-603.

20. Lam GW, Foldspang A, Elving LB et al. Social context, social abstention, and problem recognition correlated with adult female urinary incontinence. Dan Med Bull 1992;39:565-570.

21. Araoye MO. Sample size determination. In: Margaret OA, editor. Research Methodology with Statistics for Health and Social Sciences. Ilorin, Nigeria: Nathadex Publishers; 2003;P.115 9.

22. Hilton P. Urinary incontinence during sexual intercourse: a common, but rarely volunteered, symptom. Br J Obstet Gynaecol 1988;95:377381.
23. Clark A, Romm J. Effect of urinary incontinence on sexual activity in women. J Reprod Med 1993;38:679-683.

24. Sutherst JR. Sexual dysfunctional and urinary incontinence. Br J Obstet Gynaecol 1979;86:387-388.

25. Su CC, Sun BY, Jiann BP. Association of urinary incontinence and sexual function in women. Int J Urol. 2015; 22:109-13.

26. Gordon D, Groutz A, Sinai T, et al. Sexual function in women attending a urogynecology clinic. Int Urogynecol J Pelvic Floor Dysfunct 1999; 10:325-328.

27. Barber MD, Visco AG, Wyman JF, et al. Sexual function in women with urinary incontinence and pelvic organ prolapse. Obstet Gynecol 2002; 99(2):281-9.

28. Handa VL, Harvey L, Cundiff GW, et al. Sexual function among women with urinary incontinence and pelvic organ prolapse. American Journal of Obstetrics and Gynecology 2004;191(3):751-75. 